\title{
Pemilihan Alternatif Jaringan Distribusi di Kelurahan Batununggal dan Mengger, Kecamatan Bandung Kidul, Kota Bandung
}

\author{
ALYES HAKASPENO ${ }^{1}$, RACHMAWATI S.DJ ${ }^{1}$
}

\author{
1. Jurusan Teknik Lingkungan Fakultas Teknik Sipil dan Perencanaan \\ (Institut Teknologi Nasional Bandung) \\ Email: alyeshakaspeno@gmail.com
}

\begin{abstract}
ABSTRAK
Kelurahan Batununggal dan Mengger merupakan daerah cakupan pelayanan PDAM Tirtawening, dengan jumlah penduduk pada tahun 2016 sebanyak 29.190 jiwa. Walaupun tingkat pelayanan jaringan distribusi air minum daerah tersebut sebesar 24\%, tetapi pipa eksisting merupakan pipa asbes yang tua. Oleh karena itu perlu dilakukan perencanaan baru agar daerah tersebut dapat terlayani oleh jaringan PDAM dengan memanfaatkan sumber air dari IPA Cikalong. Periode perencanaan adalah 20 tahun, sampai dengan tahun 2039. Proyeksi total kebutuhan air rata-rata untuk tahun 2039 adalah sebesar 80,13 I/dtk. Perencanaan jaringan distribusi dilakukan dengan membuat 3 alternatif jaringan. Dari ketiga alternatif ini dipilih salah satu alternatif terbaik secara hidrolis dengan menggunakan metode Weight Ranking Technique (WRT). Analisis hidrolis dilakukan dengan menggunakan aplikasi Epanet 2.0, yang mengacu kepada kriteria sesuai dengan Permen PU No.18 Tahun 2007. Alternatif terpilih untuk wilayah perencanaan adalah alternatif ke-3, yaitu yang menggunakan pola gabungan (cabang dan loop). Dari hasil analisis hidrolis diperoleh sisa tekan, kecepatan aliran, dan headloss sebesar berturut-turut 15,89 m-41,60 m, 0,33 $\mathrm{m} / \mathrm{dtk}-2,08 \mathrm{~m} / \mathrm{dtk}$ dan 9,88 m/km. Pipa yang digunakan adalah jenis High Density Polyethylene (HDPE) SDR 17 PN 10.
\end{abstract}

Kata Kunci: Air Minum, Analisis Hidrolis, Jaringan Distribusi.

\begin{abstract}
ABSTRACK
Batununggal and Mengger Sub-Districts are areas that meet the services of the Tirtawening PDAM, with a total population in 2016 of 29,190 people. Although the service level of the drinking water distribution network is $24 \%$, the existing pipes are old asbestos pipes. Therefore, new planning needs to be done so that it can be served by PDAMs using sources from the Cikalong WTP. The planning period is 20 years, until 2039. The projected total average air demand for 2039 is 80.13 / / sec. Distribution network planning is done by making 3 alternative networks. From one of these alternatives Choose one of the best alternatives using the Weight Ranking Technique (WRT) method. Hydraulic analysis is carried out using the Epanet 2.0 application, which refers to criteria in accordance with Permen PU No.18 of 2007. The alternative chosen for regional planning is the 3rd alternative, which uses a pattern combination (branch and loop). From the results of the hydraulic analysis the remaining compressive pressures, flow velocity, and headloss were agreed at $15.89 \mathrm{~m}-41.60 \mathrm{~m}, 0.33 \mathrm{~m} / \mathrm{sec}-2.08 \mathrm{~m} / \mathrm{sec}$ and $9.88 \mathrm{~m} / \mathrm{km}$. The pipe used is the type of High Density Polyethylene (HDPE) SDR 17 PN 10.
\end{abstract}

Keywords: Drinking Water, Hydraulic Analysis, Distribution Networks.

[Reka Lingkungan] - 11 


\section{Pendahuluan}

Tingkat pelayanan PDAM Tirtawening di Kelurahan Batununggal dan Mengger, Kecamatan Bandung Kidul, Kota Bandung, yaitu sekitar 24\% dari jumlah penduduknya, dengan 1.406 sambungan rumah (PDAM Tirtawening, 2017), dengan demikian tingkat pelayanan PDAM Tirtawening di Kelurahan Batununggal dan Mengger belum memenuhi pelayanan air bersih kota yang tercantum pada Rencana Pembangunan Jangka Menengah Nasional (RPJMN) yang menyatakan target $100 \%$ pelayanan air bersih pada tahun 2015-2019 (Badan Perencanaan Pembangunan Nasional, 2014).

Kondisi jaringan distribusi di wilayah tersebut sudah tidak layak karena waktu penggunaan sudah cukup lama; dan pipa yang digunakan adalah asbes yang dapat membahayakan kesehatan. Selain itu, lama pengalirannya tidak mencapai 24 jam perhari, yaitu hanya berkisar antara 7-15 jam perhari (PDAM Tirtawening, 2017). Oleh karena itu, semua pipa asbes harus diganti dengan jenis pipa lain yang tidak berbahaya untuk kesehatan, yang artinya untuk wilayah ini harus dilakukan perencanaan sistem distribusi air minum yang betul-betul baru. Perencanaan sistem distribusi air minum ini dilakukan untuk memenuhi $100 \%$ kebutuhan air minum yang aman dari segi 4K (kualitas, kuantitas, kontinuitas, dan keterjangkauan), yang sesuai dengan peraturan yang berlaku.

Kelurahan Batununggal dan Mengger berada di ketinggian \pm 670 meter di atas permukaan laut (mdpl), dengan luas total sebesar 320,695 hektar (ha) seperti terlihat pada Tabel 4.1. Kelurahan Batununggal memiliki 12 Rukun Warga (RW) dan 65 Rukun Tetangga (RT); dan Kelurahan Mengger memiliki 5 RW dan 26 RT. Secara geografis Kelurahan Batununggal dan Mengger berbatasan dengan (BPS Kota Bandung, 2017):

- Bagian Utara : Kelurahan Cijagra;

- Bagian Selatan : Kabupaten Bandung;

- Bagian Timur : Kelurahan Kujangsari;

- Bagian Barat : Kelurahan Mekarwangi.

Tabel 4.1 Lokasi Daerah Perencanaan

\begin{tabular}{|c|c|l|r|r|c|}
\hline No & Kecamatan & $\begin{array}{c}\text { Desa / } \\
\text { Kelurahan }\end{array}$ & Luas (Ha) & $\begin{array}{c}\text { Koordinat } \\
\text { Bujur }\end{array}$ & $\begin{array}{c}\text { Koordinat } \\
\text { Lintang }\end{array}$ \\
\hline \multirow{2}{*}{$\mathbf{1}$} & \multirow{2}{*}{ Bandung Kidul } & Mengger & 137,195 & 107,63699 & $-6,962977$ \\
\cline { 2 - 6 } & Batununggal & 183,5 & 107,63481 & $-6,957398$ \\
\hline \multicolumn{2}{|l|}{ Total } & $\mathbf{3 2 0 , 6 9 5}$ & & \\
\hline
\end{tabular}

Sumber: BPS Kota Bandung, 2017.

\section{METODOLOGI}

Perencanaan jaringan distribusi air minum di Kelurahan Batununggal dan Mengger dilakukan dengan metode sebagai berikut.

\subsection{Studi Literatur}

Studi literatur ini dilakukan untuk mencari tinjauan pustaka mengenai teori-teori dan dasardasar perencanaan yang berhubungan dengan sistem distribusi air minum. Hasil dari tinjauan pustaka ini diperoleh kriteria desain untuk setiap parameter teknis perencanaan yang dapat dijadikan acuan perencanaan jaringan distribusi air minum di Kelurahan Batununggal dan Mengger.

\subsection{Pengumpulan Data}


Pengumpulan data disini bertujuan untuk membantu melaksanakan perancangan sistem penyediaan air minum Kelurahan Batununggal dan Mengger.

Jenis Data yang dikumpulkan meliputi:

- Data primer

Data primer adalah data yang diperoleh dari survey lapangan ataupun wawancara yang meliputi elevasi dari rencana jalur distribusi, dan jarak dari jalur yang akan dilalui jaringan distribusi.

- Data sekunder

Data sekunder yang dibutuhkan meliputi:

- Data kependudukan

Data ini diperlukan untuk menentukan proyeksi pertumbuhan penduduk di masa yang akan datang, serta untuk menghitung kebutuhan air domestik. Data tersebut bisa diperoleh dari BPS Kota Bandung;

- Data Sarana dan Prasarana

Data ini diperlukan untuk proyeksi sarana dan prasarana untuk masa yang akan datang, dan untuk menentukan kebutuhan air non-domestik daerah perencanaan;

- Peta Topografi

Peta topografi diperlukan sebagai dasar untuk menentukan sistem pengaliran jaringan distribusi, dengan menggunakan sistem gravitasi ataupun dengan sistem perpompaan. Selain itu digunakan untuk penentuan jalur dan lingkup daerah pelayanan. Data ini diperoleh dari Badan Perencanaan dan Pembangunan Daerah (BAPPEDA) Kota Bandung;

- Dokumen Rencana Tata Ruang Wilayah (RTRW)

Data ini diperlukan untuk melihat rencana pengembangan daerah perencanaan beberapa tahun ke depan. Didalam dokumen ini juga terdapat peta administrasi dan peta tata guna lahan yang menunjukkan batas-batas wilayah perencanaan dengan kawasan disekitarnya; dan dapat berguna sebagai dasar acuan penentuan penempatan jalur pipa yang akan direncanakan sesuai dengan penduduk yang akan dilayani di daerah perencanaan. Data ini didapatkan dari BAPPEDA Kota Bandung.

Metode pengumpulan data dapat dilihat pada Tabel 2.1 .

Tabel 2.1 Teknik Pengumpulan Data

\begin{tabular}{|c|c|c|c|c|c|c|c|}
\hline \multirow[b]{2}{*}{ No } & \multirow{2}{*}{$\begin{array}{l}\text { Data yang } \\
\text { Diperlukan }\end{array}$} & \multirow{2}{*}{$\begin{array}{c}\text { Tujuan } \\
\text { Pengambilan } \\
\text { Data }\end{array}$} & \multirow{2}{*}{$\begin{array}{l}\text { Jenis } \\
\text { Data }\end{array}$} & \multirow{2}{*}{$\begin{array}{l}\text { Sumber } \\
\text { Data }\end{array}$} & \multicolumn{3}{|c|}{ Teknik/Metode } \\
\hline & & & & & $\begin{array}{c}\text { Pengumpulan } \\
\text { Data }\end{array}$ & $\begin{array}{c}\text { Pengolahan } \\
\text { Data }\end{array}$ & $\begin{array}{c}\text { Analisis } \\
\text { Data }\end{array}$ \\
\hline 1. & $\begin{array}{l}\text { Data profil } \\
\text { perusahaan }\end{array}$ & $\begin{array}{l}\text { Gambaran } \\
\text { umum } \\
\text { perusahaan }\end{array}$ & $\begin{array}{l}\text { Sekunder, } \\
\text { Kualitatif }\end{array}$ & $\begin{array}{l}\text { PDAM } \\
\text { Tirtawening }\end{array}$ & $\begin{array}{l}\text { Studi } \\
\text { dokumentasi }\end{array}$ & Deskriptif & Deskriptif \\
\hline 2. & $\begin{array}{l}\text { Kondisi eksisting: } \\
\text { 1. Jalur distribusi } \\
\text { (elevasi, debit) } \\
\text { 2. Peta Jaringan } \\
\text { 3. Peta Cakupan } \\
\text { Wilayah } \\
\text { 4. Peta Jalan }\end{array}$ & $\begin{array}{l}\text { Perhitungan } \\
\text { dan evaluasi } \\
\text { permasalahan } \\
\text { yang terjadi }\end{array}$ & $\begin{array}{l}\text { Primer, } \\
\text { kualitatif } \\
\text { Sekunder, } \\
\text { kuantitatif }\end{array}$ & $\begin{array}{l}\text { PDAM } \\
\text { Tirtawening }\end{array}$ & $\begin{array}{c}\text { Studi } \\
\text { dokumentasi, } \\
\text { Observasi, dan } \\
\text { Wawancara }\end{array}$ & Matematis & $\begin{array}{l}\text { Matematis, } \\
\text { komparatif, } \\
\text { deskriptif }\end{array}$ \\
\hline 3. & $\begin{array}{l}\text { Data cakupan } \\
\text { pelayanan }\end{array}$ & $\begin{array}{l}\text { Perhitungan } \\
\text { kuantitas air } \\
\text { minum } \\
\text { pelayanan }\end{array}$ & $\begin{array}{l}\text { Sekunder, } \\
\text { kuantitatif }\end{array}$ & $\begin{array}{l}\text { PDAM } \\
\text { Tirtawening }\end{array}$ & $\begin{array}{l}\text { Studi } \\
\text { dokumentasi }\end{array}$ & Matematis & $\begin{array}{l}\text { Matematis, } \\
\text { Deskriptif }\end{array}$ \\
\hline 4. & Data pelanggan & $\begin{array}{l}\text { Perhitungan } \\
\text { penggunaan }\end{array}$ & $\begin{array}{l}\text { Sekunder, } \\
\text { kuantitatif }\end{array}$ & $\begin{array}{l}\text { PDAM } \\
\text { Tirtawening }\end{array}$ & $\begin{array}{l}\text { Studi } \\
\text { dokumentasi }\end{array}$ & Matematis & $\begin{array}{l}\text { Matematis, } \\
\text { Deskriptif }\end{array}$ \\
\hline
\end{tabular}

[Reka Lingkungan] - 13 


\begin{tabular}{|c|c|c|c|c|c|c|c|}
\hline \multirow[b]{2}{*}{ No } & \multirow{2}{*}{$\begin{array}{l}\text { Data yang } \\
\text { Diperlukan }\end{array}$} & \multirow{2}{*}{$\begin{array}{c}\text { Tujuan } \\
\text { Pengambilan } \\
\text { Data }\end{array}$} & \multirow{2}{*}{$\begin{array}{l}\text { Jenis } \\
\text { Data }\end{array}$} & \multirow{2}{*}{$\begin{array}{l}\text { Sumber } \\
\text { Data }\end{array}$} & \multicolumn{3}{|c|}{ Teknik/Metode } \\
\hline & & & & & $\begin{array}{c}\text { Pengumpulan } \\
\text { Data }\end{array}$ & $\begin{array}{c}\text { Pengolahan } \\
\text { Data }\end{array}$ & $\begin{array}{c}\text { Analisis } \\
\text { Data }\end{array}$ \\
\hline & & $\begin{array}{l}\text { air/pemakaian } \\
\text { air rata-rata }\end{array}$ & & & & & \\
\hline 5. & $\begin{array}{l}\text { Data Peraturan } \\
\text { Terkait }\end{array}$ & $\begin{array}{l}\text { Standar / } \\
\text { Acuan } \\
\text { Perencanaan }\end{array}$ & $\begin{array}{l}\text { Sekunder, } \\
\text { kualitatif, } \\
\text { kuantitatif }\end{array}$ & $\begin{array}{l}\text { Bappenas, } \\
\text { Departemen } \\
\text { Pekerjaan } \\
\text { Umum }\end{array}$ & $\begin{array}{l}\text { Studi } \\
\text { dokumentasi }\end{array}$ & Deskriptif & $\begin{array}{l}\text { Komparatif, } \\
\text { Deskriptif }\end{array}$ \\
\hline 6. & $\begin{array}{l}\text { Program Epanet } \\
2.0\end{array}$ & $\begin{array}{l}\text { Analisis } \\
\text { hidrolis }\end{array}$ & $\begin{array}{l}\text { Primer, } \\
\text { kuantitatif }\end{array}$ & $\begin{array}{l}\text { PDAM } \\
\text { Tirtawening }\end{array}$ & Studi observasi & Matematis & Matematis \\
\hline
\end{tabular}

\subsection{Pengolahan Data}

Setelah data-data terkumpul, data tersebut diolah dengan menggunakan beberapa metode perhitungan. Untuk menghitung proyeksi penduduk sampai dengan akhir tahun perencanaan, maka data penduduk dihitung dengan menggunakan metoda geometrik, aritmatik dan least square. Metode proyeksi penduduk untuk perencanaan ini dipilih berdasarkan nilai korelasi, rata-rata, standar deviasi, nilai coefficient variance (CV), dan rencana pengembangan wilayahnya. Kehilangan tekanan (headloss) dihitung dengan menggunakan formula Hazen-Williams dalam program komputer Epanet 2.0.

\subsection{Perancangan Jaringan Pipa Distribusi}

Perancangan Jaringan Pipa Distribusi ini Mencakup:

1. Pembuatan Alternatif Sistem

Penyusunan alternatif ini digunakan untuk mencari jalur sistem yang paling memungkinkan, dan benar secara hidrolis. Untuk itu direncanakan 3 skenario alternatif jaringan yang dibuat dengan variasi yang berbeda;

2. Menghitung Dimensi Pipa Distribusi

Perhitungan dimensi pipa distribusi dilakukan dengan melihat faktor teknis, seperti kecepatan maksimum dan minimum; sisa tekan maksimum dan minimum; serta headloss maksimum;

3. Penentuan Aksesoris Perpipaan

Aksesoris perpipaan adalah alat penunjang pipa distribusi agar perpipaan tersebut dapat terpasang dengan baik, sehingga penyaluran air minum bisa berjalan sesuai perencanaan;

4. Pemilihan Alternatif Sistem

Jaringan pipa distribusi harus dipilih dengan mempertimbangkan faktor teknis dan ekonomis agar jalur pipa distribusi tersebut dapat dipasang sesuai dengan kebutuhan dan kondisi di lapangan. Faktor yang paling penting adalah dimensi dan diameter pipa yang sesuai dengan kebutuhan air minum pada daerah perencanaan yang harus memenuhi parameter-parameter teknis, seperti kecepatan minimum sebesar 0,3 m/detik; kecepatan maksimum sebesar 2,0 $\mathrm{m} /$ detik; tekanan minimum sebesar $10 \mathrm{~m}$; tekanan maksimum sebesar 10 bar untuk pipa HDPE; dan headloss maksimum sebesar $10 \mathrm{~m} / \mathrm{km}$ (PerMen PU no. 18 tahun 2007). Pemilihan alternatif dilakukan dengan menggunakan Metoda pemeringkatan dengan pembobotan (weighted ranking technique/WRT) dan Metode Checklist, 


\subsection{Langkah Kerja Perencanaan}

Langkah kerja proses perancangan sistem distribusi air minum dapat dilihat pada Gambar 2.1.

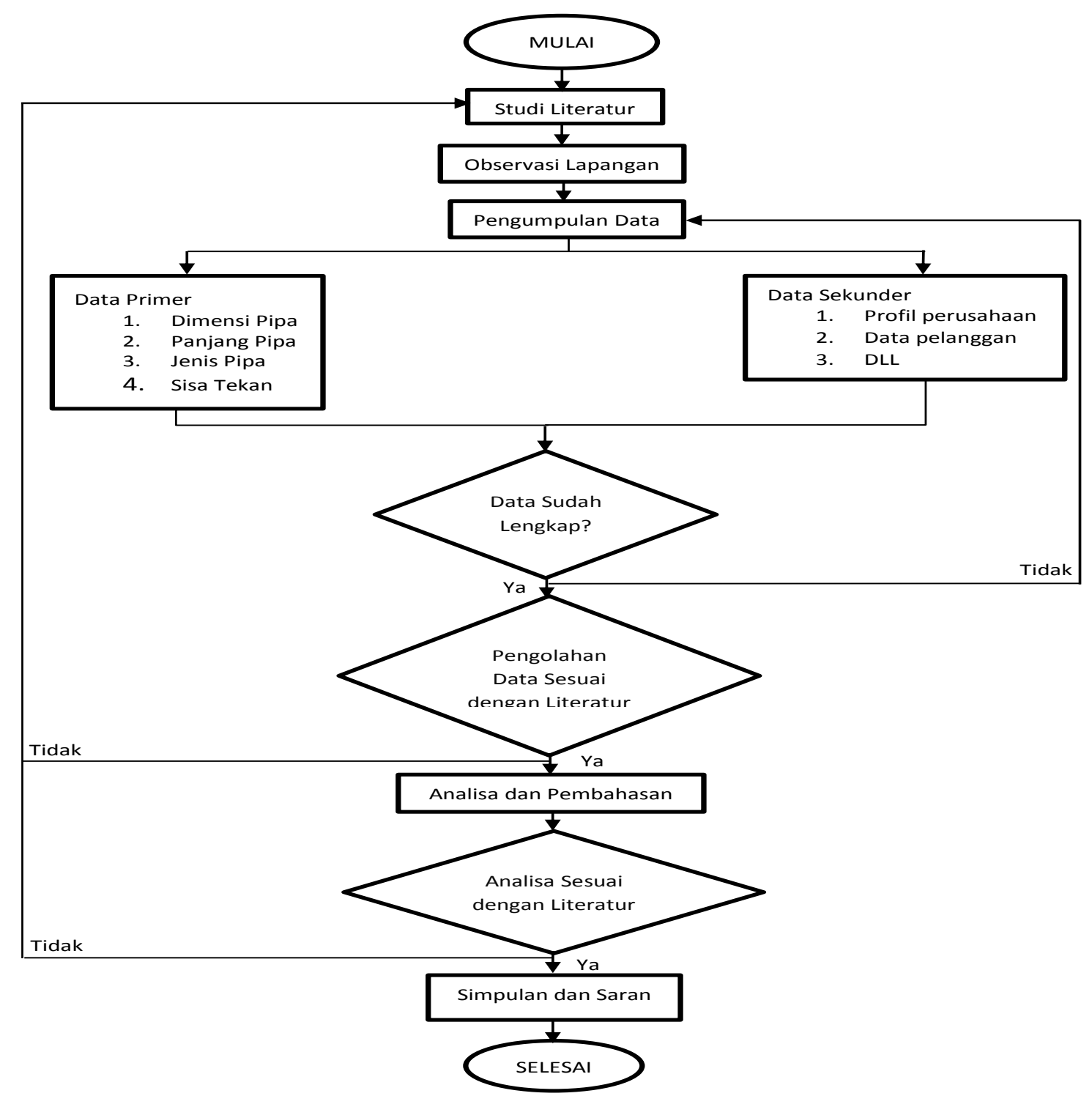

Gambar 2.1 Langkah Kerja Perencanaan

\subsection{Proyeksi Penduduk}

\section{HASIL PEMBAHASAN}

Proyeksi jumlah penduduk dilakukan untuk menghitung pertambahan penduduk hingga akhir tahun perencanaan. Metode proyeksi yang digunakan, yaitu metode aritmatik, geometri, dan least square. Setelah itu, dilakukan analisis secara matematis dengan cara menghitung standar deviasi, koefisien variansi, dan korelasi. Dari hasil analisis diperoleh bahwa metode proyeksi geometri merupakan metoda yang sesuai untuk daerah perencanaan. Pada Tabel 3.1 dapat dilihat perbandingan proyeksi penduduk dan pada Tabel $\mathbf{3 . 2}$ dapat dilihat hasil proyeksi penduduk dengan menggunakan metode geometri. 
Tabel 3.1 Perbandingan Metode Proyeksi Penduduk

\begin{tabular}{|c|c|c|c|c|}
\hline \multirow[b]{2}{*}{ Tahun } & \multirow{2}{*}{$\begin{array}{c}\text { Penduduk } \\
\text { Eksiting }\end{array}$} & \multicolumn{3}{|c|}{ PROYEKSI PENDUDUK } \\
\hline & & $\begin{array}{c}\text { Metode } \\
\text { Aritmatika }\end{array}$ & $\begin{array}{l}\text { Metode } \\
\text { Geometri }\end{array}$ & $\begin{array}{c}\text { Metode Least } \\
\text { Square }\end{array}$ \\
\hline 2007 & 24.189 & 24.189 & 24.189 & 23.651 \\
\hline 2008 & 24.580 & 24.744 & 24.664 & 24.315 \\
\hline 2009 & 25.011 & 25.298 & 25.147 & 24.979 \\
\hline 2010 & 25.477 & 25.853 & 25.641 & 25.643 \\
\hline 2011 & 25.943 & 26.407 & 26.144 & 26.308 \\
\hline 2012 & 26.352 & 26.962 & 26.657 & 26.972 \\
\hline 2013 & 26.551 & 27.516 & 27.179 & 27.636 \\
\hline 2014 & 27.816 & 28.071 & 27.713 & 28.300 \\
\hline 2015 & 31.298 & 28.625 & 28.256 & 28.965 \\
\hline 2016 & 29.180 & 29.180 & 28.811 & 29.629 \\
\hline \multicolumn{2}{|c|}{ Standar Deviasi (SD) } & $1.679,000324$ & $1.554,658889$ & $2.011,11216$ \\
\hline \multicolumn{2}{|c|}{ Koefisien Variansi (CV) } & $2.819 .042,088$ & $2.416 .964,26$ & $4.044 .572,122$ \\
\hline \multicolumn{2}{|c|}{ Korelasi $\left(r_{x y}\right)$} & 0,905806073 & 0,909973174 & 0,905806073 \\
\hline
\end{tabular}

Sumber: Analisis, 2019

Metode proyeksi terbaik adalah metode yang memiliki (Soleh, 2006):

1. Nilai SD yang paling kecil;

2. Nilai CV yang paling kecil;

3. Nilai $r_{x y}$ yang paling besar (paling mendekati nilai 1 ).

Dari Tabel 3.1 dapat dilihat bahwa nilai standar deviasi dan koefisien variansi paling kecil , serta nilai korelasi paling besar terdapat pada metode geometri. Oleh karena itu, dapat disimpulkan bahwa metode proyeksi yang dipilih adalah metode proyeksi geometri.

Tabel 3.2 Proyeksi Penduduk dengan Metode Geometri

\begin{tabular}{|c|c|c|}
\hline No & Tahun & Jumlah Penduduk (Jiwa) \\
\hline 1 & 2019 & 30.540 \\
\hline 2 & 2024 & 33.665 \\
\hline 3 & 2029 & 37.088 \\
\hline 4 & 2034 & 40.872 \\
\hline 5 & 2039 & 45.041 \\
\hline
\end{tabular}

Sumber: Analisis, 2019

\subsection{Proyeksi Kebutuhan Air}

Untuk mengetahui kebutuhan air di Kelurahan Batununggal dan Mengger, dilakukan proyeksi kebutuhan air yang disesuaikan dengan metode terpilih proyeksi penduduk. Direncanakan pada tahun 2039 sudah 100\% terlayani. Total kebutuhan air rata-rata pada akhir tahun 2039 adalah sebanyak 80,13 liter/detik. Hal ini terjadi karena adanya peningkatan jumlah penduduk di wilayah perencanaan yang mencapai 45.041 jiwa. Pada Tabel 3.3 dapat dilihat rekapitulasi kebutuhan air di Kelurahan Batununggal dan Mengger. 
Tabel 3.3 Rekapitulasi Kebutuhan Air Domestik dan Non Domestik

\begin{tabular}{|c|c|c|c|c|c|c|c|c|c|}
\hline \multirow{2}{*}{ No } & \multirow{2}{*}{ Uraian } & \multirow{2}{*}{ Satuan } & \multirow{2}{*}{\begin{tabular}{|c|} 
Eksisting \\
2016 \\
\end{tabular}} & \multicolumn{5}{|c|}{ Tahun Perencanaan } & \multirow{2}{*}{ Sumber } \\
\hline & & & & 2019 & 2024 & 2029 & 2034 & 2039 & \\
\hline \multicolumn{9}{|c|}{\begin{tabular}{l|l|} 
A & Penduduk \\
\end{tabular}} & \\
\hline 1 & Jumlah Penduduk & jiwa & 29.180 & 30.540 & 33.655 & 37.088 & 40.872 & 45.041 & Proyeksi Penduduk \\
\hline 2 & Konsumsi Air & I/org/hari & 121,1949 & 120 & 120 & 120 & 120 & 120 & Permen PU No.14/PRT/M/2010 \\
\hline 3 & Tingkat Pelayanan (\%) & $x 100$ & 0,24 & 0,50 & 0,75 & 1,00 & 1,00 & 1,00 & \\
\hline 4 & Jumlah Penduduk Yang Dilayani & jiwa & 7.030 & 15.270 & 25.241 & 37.088 & 40.872 & 45.041 & PDAM Tirta Wening \\
\hline 5 & Jumlah Penduduk Per SR & jiwa & 5 & 5 & 5 & 5 & 5 & & Standar PDAM Tirta Wening \\
\hline \multicolumn{9}{|c|}{ Kebutuhan Domestik } & \\
\hline \multirow{13}{*}{ B } & \multicolumn{8}{|c|}{ Perpipaan (SR) } & \\
\hline & Sistem Perpipaan (\%) & $\mathrm{x} 100$ & & 0,60 & 0,65 & 0,70 & 0,75 & 0,80 & \\
\hline & Jumlah Penduduk yang Dilayani & jiwa & - & 9162 & 16407 & 25962 & 30654 & 36033 & Perhitungan \\
\hline & Jumlah Penduduk Per SR & jiwa & & 5 & 5 & 5 & 5 & 5 & Standar PDAM Tirta Wening \\
\hline & \begin{tabular}{|l|} 
Jumlah Sambungan Rumah \\
\end{tabular} & SR & - & 1832 & 3281 & 5192 & 6131 & 7207 & Perhitungan \\
\hline & Kebutuhan Air SR & l/dtk & & 12,7249 & 22,7873 & 36,0580 & 42,5746 & 50,0455 & Perhitungan \\
\hline & \multicolumn{8}{|c|}{ Non Perpipaan (HU) } & \\
\hline & Sistem Non Perpipaan (\%) & $\mathrm{x} 100$ & - & 0,40 & 0,35 & 0,30 & 0,25 & 0,20 & \\
\hline & Jumlah Penduduk Yang Dilayani & I/dtk & 7 & 6108 & 8834 & 11126 & 10218 & 9008 & Perhitungan \\
\hline & Jumlah Jiwa Per HU & I/dtk & - & 100 & 100 & 100 & 100 & 100 & \\
\hline & Jumlah HU & $\mathrm{HU}$ & - & 61 & 88 & 111 & 102 & 90 & Perhitungan \\
\hline & Kebutuhan Air HU & l/dtk & & 8,4832 & 12,2701 & 15,4534 & 14,1915 & 12,5114 & Perhitungan \\
\hline & Total Kebutuhan Domestik & I/dtk & 9,8611 & 21,2081 & 35,0573 & 51,5114 & 56,7661 & 62,5569 & Perhitungan \\
\hline C & Kebutuhan Non Domestik & I/dtk & 3,3888 & 3,4601 & 3,6237 & 3,8039 & 4,0025 & 4,2214 & Perhitungan \\
\hline \multirow[t]{2}{*}{$\mathrm{D}$} & Kebutuhan Total $(B+C)$ & I/dtk & 13,2499 & 24,6682 & 38,6810 & 55,3153 & 60,7686 & 66,7783 & Perhitungan \\
\hline & \multicolumn{8}{|l|}{ Kehilangan Air } & \\
\hline \multirow[t]{2}{*}{$\mathbf{E}$} & \% kehilangan & $\%$ & 0,30 & 0,20 & 0,20 & 0,20 & 0,20 & 0,20 & Permen PU No.18 thn 2007 \\
\hline & debit kehilangan air & I/dtk & 3,9750 & 4,9336 & 7,7362 & 11,0631 & 12,1537 & 13,3557 & Perhitungan \\
\hline \multirow[t]{2}{*}{$\mathbf{F}$} & Kebutuhan Air Rata-rata (D+E) & $\mathrm{l} / \mathrm{dtk}$ & 17,2248 & 29,6019 & 46,4172 & 66,3784 & 72,9224 & 80,1339 & Perhitungan \\
\hline & \multicolumn{8}{|l|}{ Kebutuhan Hari Maksimum } & \\
\hline \multirow[t]{2}{*}{ G } & a. Faktor Koefisien & & 1,1 & 1,1 & 1,1 & 1,1 & 1,1 & 1,1 & PDAM Tirta Wening \\
\hline & b. Kebutuhan Air & I/dtk & 18,9473 & 32,5621 & 51,0589 & 73,0162 & 80,2146 & 88,1473 & Perhitungan \\
\hline \multirow{3}{*}{ H } & \multicolumn{8}{|l|}{ Kebutuhan Jam Puncak } & \\
\hline & a. Faktor Koefisien & & 1,13 & 1,13 & 1,13 & 1,13 & 1,13 & 1,13 & PDAM Tirta Wening \\
\hline & b. Kebutuhan Air & I/dtk & 19,4641 & 33,4501 & 52,4514 & 75,0076 & 82,4023 & 90,5513 & Perhitungan \\
\hline
\end{tabular}

Sumber: Analisis, 2019

\subsection{Alternatif Jaringan Distribusi}

Air minum harus dialirkan secara baik dan optimal kepada konsumen, sehingga perencanaan jaringan distribusi air minum perlu memperhatikan hal-hal berikut ini:

1. Jaringan yang dibuat memenuhi syarat hidrolis;

2. Kontinuitas pelayanan terpenuhi dengan baik;

3. Jaringan dibuat dengan biaya seminimal mungkin.

Perencanaan alternatif jaringan distribusi dilakukan dengan menggunakan software Epanet 2.0. Untuk memperoleh sistem distribusi terbaik, maka dibuat tiga alternatif jaringan distribusi. Ketiga alternatif memiliki pola yang berbeda-beda, yaitu alternatif 1 (satu) dengan metoda cabang, alternatif 2 (dua) dengan metoda loop, dan alternatif 3 (tiga) dengan metoda gabungan (cabang dan loop). Pipa yang digunakan adalah pipa jenis High Density Polyethylene (HDPE) SDR 17 PN-10. Pertimbangan pemakaian pipa HDPE ini karena karakternya yang tidak mudah rusak dan bahkan tahan terhadap suhu hingga 60 derajat Celcius. Selain itu, pipa HDPE juga direkomendasikan untuk saluran air minum bertekanan yang mencapai 10 bar; dan berstandar food grade yang artinya aman untuk saluran air minum kebutuhan konsumsi. Diameter yang digunakan pada setiap alternatif bervariasi antara $40 \mathrm{~mm}-280 \mathrm{~mm}$. Jam puncak pada daerah pelayanan terjadi pada jam 18.00 Waktu Indonesia Barat (WIB). 


\subsubsection{Alternatif Satu}

Perencanaan jaringan distribusi pada alternatif satu menggunakan metoda cabang dengan pola jaringan mengikuti jaringan jalan yang ada, sehingga memudahkan pada saat pemasangan serta perawatan. Sistem pengaliran dilaksanakan secara kontinu atau selama 24 jam. Tabel $\mathbf{3 . 4}$ menunjukkan hasil analisis pada jaringan pipa alternatif satu.

Tabel 3.4 Hasil Running Epanet 2.0 untuk Alternatif Satu

\begin{tabular}{|l|r|l|}
\hline Elevasi & $666-860$ & meter \\
\hline Panjang Pipa & 45.655 & meter \\
\hline Tekanan Minimun & 13,99 & meter \\
\hline Tekanan Maksimum & 41,60 & meter \\
\hline Kecepatan Minimum & 0,30 & meter/detik \\
\hline Kecepatan Maksimum & 2,08 & meter/detik \\
\hline Headloss & 10,00 & meter/kilometer \\
\hline
\end{tabular}

Sumber: Hasil Perhitungan, 2019

\subsubsection{Alternatif Dua}

Perencanaan jaringan disrtibusi pada alternatif dua menggunakan metoda loop. Sistem pengaliran dilaksanakan secara kontinu selama 24 jam. Tabel 3.5 menunjukkan hasil analisis jaringan pipa alternatif dua.

Tabel 3.5 Hasil Running Epanet 2.0 untuk Alternatif Dua

\begin{tabular}{|l|r|l|}
\hline Elevasi & $666-860$ & meter \\
\hline Panjang Pipa & 30.584 & meter \\
\hline Tekanan Minimun & 17,66 & meter \\
\hline Tekanan Maksimum & 41,60 & meter \\
\hline Kecepatan Minimum & 0,00 & meter/detik \\
\hline Kecepatan Maksimum & 2,08 & meter/detik \\
\hline Headloss & 9,8 & meter/kilometer \\
\hline
\end{tabular}

Sumber: Hasil Perhitungan, 2019.

\subsubsection{Alternatif Tiga}

Perencanaan jaringan disrtibusi pada alternatif tiga menggunakan metoda cabang, untuk pengaliran selama 24 jam.

Tabel 3.6 Hasil Running Epanet 2.0 untuk Alternatif Tiga

\begin{tabular}{|l|r|l|}
\hline Elevasi & $666-860$ & meter \\
\hline Panjang Pipa & 47.074 & meter \\
\hline Tekanan Minimun & 15,89 & meter \\
\hline Tekanan Maksimum & 41,60 & meter \\
\hline Kecepatan Minimum & 0,33 & meter/detik \\
\hline Kecepatan Maksimum & 2,08 & meter/detik \\
\hline Headloss & 9,88 & meter/kilometer \\
\hline
\end{tabular}

\subsection{Pemilihan Alternatif dengan Weight Ranking Technique Method}

Penggunaan metode ini sangat umum digunakan untuk membandingkan beberapa alternatif perencanaan. Weight Ranking Technique Methode (WRT) atau pembobotan merupakan metode yang memberikan nilai terhadap setiap parameter yang dibandingkan, sehingga nilainya pun juga bersifat kuantitatif (Khodijah, 2000). 


\subsubsection{Perbandingan Alternatif}

Ketiga alternatif yang sudah direncanakan dibandingkan berdasarkan kriteria pemilihan jalur, pola jaringan, panjang pipa, tekanan dalam pipa, nilai headloss, dan kecepatan aliran. Khusus untuk pertimbangan ekonomi, maka yang dilakukan hanya secara kualitatif dengan memperkirakan banyaknya pipa dan aksesoris yang akan digunakan. Pada Tabel 3.7 dapat dilihat perbandingan alternatif berdasarkan kriteria-kriteria yang telah disebutkan.

Kelurahan Batununggal dan Mengger terdiri dari komplek-komplek perumahan berkepadatan sedang dengan kondisi jaringan jalan yang berhubungan satu sama lain, serta kondisi topografi yang relatif datar. Akan tetapi, di sebagian wilayah perencanaan masih terdapat daerah perumahan padat dengan kondisi jalan yang tidak berhubungan. Secara umum, ketiga alternatif jalur pipa distribusi mengikuti jaringan jalan yang telah dibangun.

Tabel 3.7 Perbandingan ketiga alternatif

\begin{tabular}{|l|l|l|l|}
\hline \multicolumn{1}{|c|}{ Kriteria } & \multicolumn{1}{|c|}{ Alternatif 1 } & \multicolumn{1}{c|}{ Alternatif 2 } & \multicolumn{1}{c|}{ Alternatif 3 } \\
\hline Pemilihan jalur distribusi & $\begin{array}{l}\text { Mengikuti pola jaringan } \\
\text { jalan }\end{array}$ & $\begin{array}{l}\text { Mengikuti pola jaringan } \\
\text { jalan }\end{array}$ & $\begin{array}{l}\text { Mengikuti pola jaringan } \\
\text { jalan }\end{array}$ \\
\hline Pola Jaringan & Cabang & Loop & Gabungan \\
\hline Panjang Pipa & $45.654,66 \mathrm{~m}$ & $30.584 \mathrm{~m}$ & $47.074 \mathrm{~m}$ \\
\hline Tekanan Dalam Pipa & Memenuhi kriteria & Memenuhi kriteria & Memenuhi kriteria \\
\hline Nilai Headloss & Memenuhi kriteria & Memenuhi kriteria & Memenuhi kriteria \\
\hline Kecepatan & Memenuhi kriteria & $\begin{array}{l}\text { Tidak } \\
\text { Memenuhi kriteria }\end{array}$ & Memenuhi kriteria \\
\hline
\end{tabular}

Sumber: Hasil Perhitungan, 2019

Tekanan yang diperbolehkan, yaitu $>10 \mathrm{~m}$ karena dengan tekanan sebesar ini air dapat mengalir ke konsumen dengan lancar. Oleh karena itu, digunakan pipa HDPE yang mempunyai tekanan maksimum mencapai 10 bar atau $100 \mathrm{~m}$. Kecepatan minimum sebesar 0,3 m/dtk diperlukan agar tidak terjadi endapan pada pipa yang diakibatkan oleh Suspended Solid (SS) yang terlarut dalam air, sehingga dapat menyebabkan terganggunya sistem perpipaan. Sedangkan untuk headloss harus $<10 \mathrm{~m} / \mathrm{km}$ karena apabila melebihi nilai ini, dikhawatirkan kehilangan tekanan menjadi besar yang akan menimbulkan masalah pada ketersediaan air di titik terjauh.

\subsubsection{Penentuan Nilai Koefisien Pentingnya Faktor}

Hal pertama yang dilakukan dalam menentukan pemilihan alternatif dengan metode WRT, yaitu mencari nilai Koefisien Pentingnya Faktor (KPF). Nilai yang akan diberikan pada perbandingan adalah 0 sebagai parameter tidak penting; 0,5 sebagai parameter sama penting; dan 1 sebagai parameter lebih penting. Untuk mengetahui jumlah parameter yang digunakan pada proses penilaian, maka perlu dilakukan perhitungan sebagai berikut (Khodijah, 2000):

$$
\text { Jumlah Kolom }=\frac{\mathrm{N}(\mathrm{N}-1)}{2}
$$

Nilai $\mathrm{N}$ merupakan jumlah parameter yang digunakan dalam pemilihan alternatif. Untuk metode ini nilai $\mathrm{N}$ adalah 5 , maka nilai jumlah kolom yang dipakai adalah sebagai berikut:

$$
\text { Jumlah Kolom }=\frac{5(5-1)}{2}=10 \text { Kolom }
$$

Tahapan proses penilaian untuk setiap parameter teknis dapat dilihat lebih jelas pada Tabel 3.8 . 
Tabel 3.8 Perhitungan Nilai Koefisien Pentingnya Faktor Persyaratan Teknis

\begin{tabular}{|l|c|c|c|c|c|c|c|c|c|c|c|c|}
\hline \multirow{2}{*}{ Parameter } & $\mathbf{1}$ & $\mathbf{2}$ & $\mathbf{3}$ & $\mathbf{4}$ & $\mathbf{5}$ & $\mathbf{6}$ & $\mathbf{7}$ & $\mathbf{8}$ & $\mathbf{9}$ & $\mathbf{1 0}$ & Jumlah & KPF \\
\hline $\begin{array}{l}\text { Kecepatan } \\
\text { Minimum } \\
\text { (m/dtk) }\end{array}$ & 1 & 0 & 0,5 & 0 & & & & & & & 1,5 & 0,15 \\
\hline $\begin{array}{l}\text { Kecepatan } \\
\text { Maksimum } \\
\text { (m/dtk) }\end{array}$ & 0 & & & & 0 & 0,5 & 0,5 & & & & 1 & 0,10 \\
\hline $\begin{array}{l}\text { Tekanan } \\
\text { Minimum (m) }\end{array}$ & 1 & & 1 & & & 1 & 1 & & 4 & 0,40 \\
\hline $\begin{array}{l}\text { Tekanan } \\
\text { Maksimum } \\
\text { (m) }\end{array}$ & & 0,5 & & & 0,5 & & 0 & & 0 & 1 & 0,10 \\
\hline $\begin{array}{l}\text { Headloss } \\
\text { (m/km) }\end{array}$ & & & 1 & & & 0,5 & & 0 & 1 & 2,5 & 0,25 \\
\hline
\end{tabular}

Sumber: Hasil Perhitungan, 2019

\subsubsection{Penentuan Nilai Koefisien Pemilihan Alternatif}

Tahap kedua, yaitu menentukan nilai Koefisien Pemilihan Alternatif (KPA) dengan nilai 0 sebagai parameter tidak penting; 0,5 sebagai parameter sama penting; dan 1 sebagai parameter lebih penting. Nilai setiap parameter untuk masing-masing alternatif dapat dilihat pada Tabel 3.9.

Perhitungan Nilai KPA untuk tekanan minimum dan tekanan maksimum pada alternatif 1,2, dan 3 adalah sama-sama memiliki nilai 0,5 karena tekanan minimum pada seluruh alternatif sesuai dengan standar kriteria desain. Nilai kecepatan minimum pada alternatif 1 dan 3, yaitu 0,5 berbeda dengan alternatif 2, yaitu 0 . Hal ini disebabkan karena pada alternatif 2 tidak memenuhi standar kriteria desain. Sementara itu untuk kecepatan maksimum pada semua alternatif memiliki nilai yang sama, yaitu 0,5 . Pada parameter headloss untuk alternatif 1 memiliki nilai 0 berbeda dengan alternatif 2 dan 3 yang memiliki nilai 0,5 yang sesuai dengan standar kriteria desain.

Tabel 3.9 Perhitungan Nilai Koefisien Pemilihan Alternatif Persyaratan Teknis

\begin{tabular}{|c|l|c|}
\hline \multirow{2}{*}{ No } & \multicolumn{1}{|c|}{ Parameter dan Pola Distribusi } & KPA \\
\hline 1 & Tekanan Minimum & \\
\hline & Alternatif 1 Cabang (13,99 meter) & 0,5 \\
\hline & Alternatif 2 Loop (17,66 meter) & 0,5 \\
\hline & Alternatif 3 Gabungan (15,89 meter) & 0,5 \\
\hline & Jumlah & $\mathbf{1 , 5}$ \\
\hline 2 & Tekanan Maksimum (41,60 meter) & 0,5 \\
\hline & Alternatif 1 Cabang (41,60 meter) & 0,5 \\
\hline & Alternatif 2 Loop & 0,5 \\
\hline & Alternatif 3 Gabungan (41,60 meter) & $\mathbf{1 , 5}$ \\
\hline 3 & Jumlah & \\
\hline & Kecepatan Minimum (0,30 meter/detik) & 0,5 \\
\hline & Alternatif 1 Cabang (0,00 meter/detik) & 0 \\
\hline & Alternatif 2 Loop & 0,5 \\
\hline & Alternatif 3 Gabungan (0,33 meter/detik) & $\mathbf{1}$ \\
\hline 4 & Jumlah & \\
\hline & Kecepatan Maksimum & 0,5 \\
\hline & Alternatif 1 Cabang (2,08 meter/detik) & 0,5 \\
\hline & Alternatif 2 Loop (2,08 meter/detik) & 0,5 \\
\hline & Alternatif 3 Gabungan (2,08 meter/detik) & $\mathbf{1 , 5}$ \\
\hline 5 & Jumlah & \\
\hline & Headloss & \\
\hline
\end{tabular}

[Reka Lingkungan] - 20 


\begin{tabular}{|c|c|c|}
\hline No & Parameter dan Pola Distribusi & KPA \\
\hline & Alternatif 1 Cabang $\quad(10,00 \mathrm{~m} / \mathrm{Km})$ & 0 \\
\hline & Alternatif 2 Loop $\quad(9,80 \mathrm{~m} / \mathrm{Km})$ & 0,5 \\
\hline & Alternatif 3 Gabungan $(9,88 \mathrm{~m} / \mathrm{Km})$ & 0,5 \\
\hline & Jumlah & 1 \\
\hline
\end{tabular}

Sumber: Hasil Perhitungan, 2019

\subsubsection{Penentuan Alternatif Optimalisasi Jalur Distribusi Terbaik}

Tahapan terakhir dalam metode WRT adalah tahap pengambilan keputusan. Nilai KPF dan KPA yang telah ditentukan pada tabel sebelumnya dijumlahkan. Setelah didapatkan nilai akhir pada setiap alternatif, maka alternatif dengan nilai akhir paling besar adalah alternatif terpilih. Selengkapnya dapat dilihat pada Tabel 3.10.

Berdasarkan hasil perhitungan dengan menggunakan metode WRT, didapatkan kesimpulan bahwa pemilihan alternatif optimalisasi jalur distribusi terbaik adalah alternatif 3 , yaitu jaringan distribusi air minum dengan pola gabungan (cabang dan loop). Alternatif tersebut memiliki hasil perkalian KPA dan KPF lebih besar dibandingkan alternatif 1 dan 2.

Tabel 3.10 Pemilihan Alternatif Optimalisasi Jalur Distribusi Terbaik

\begin{tabular}{|c|c|c|c|c|c|c|c|c|}
\hline \multirow[b]{2}{*}{ No } & \multirow[b]{2}{*}{ Parameter } & \multirow[b]{2}{*}{ KPF } & \multicolumn{3}{|c|}{ KPA } & \multicolumn{3}{|c|}{ KPA $\times$ KPF } \\
\hline & & & $\begin{array}{c}\text { Alternatif } \\
1\end{array}$ & $\begin{array}{c}\text { Alternatif } \\
2\end{array}$ & $\begin{array}{c}\text { Alternatif } \\
3\end{array}$ & $\begin{array}{c}\text { Alternatif } \\
1\end{array}$ & $\begin{array}{c}\text { Alternatif } \\
2\end{array}$ & $\begin{array}{c}\text { Alternatif } \\
3\end{array}$ \\
\hline 1 & $\begin{array}{l}\text { Tekanan } \\
\text { Minimum } \\
\text { (m) }\end{array}$ & 0,4 & 0,5 & 0,5 & 0,5 & 0,2 & 0,2 & 0,200 \\
\hline 2 & $\begin{array}{l}\text { Tekanan } \\
\text { Maksimum } \\
\text { (m) }\end{array}$ & 1 & 0,5 & 0,5 & 0,5 & 0,5 & 0,5 & 0,5 \\
\hline 3 & $\begin{array}{l}\text { Kecepatan } \\
\text { Minimum } \\
(\mathrm{m} / \mathrm{dtk})\end{array}$ & 0,15 & 0,5 & 0 & 0,5 & 0,075 & 0 & 0,075 \\
\hline 4 & $\begin{array}{l}\text { Kecepatan } \\
\text { Maksimum } \\
\text { (m/dtk) }\end{array}$ & 1 & 0,5 & 0,5 & 0,5 & 0,5 & 0,5 & 0,5 \\
\hline 5 & $\begin{array}{l}\text { Headloss } \\
(\mathrm{m} / \mathrm{Km})\end{array}$ & 0,25 & 0 & 0,5 & 0,5 & 0 & 0,125 & 0,125 \\
\hline & & & & & Jumlah & 1,275 & 1,325 & 1,4 \\
\hline
\end{tabular}

Sumber: Hasil Perhitungan, 2019

\section{KESIMPULAN}

- Setelah dilakukan perhitungan dan analisis dengan menggunakan metode WRT terhadap alternatif jaringan distribusi 1, 2, dan 3 pada jaringan distribusi air minum di Kelurahan Batununggal dan Mengger didapat hasil pemilihan jaringan terbaik, yaitu alternatif 3 dengan pola jaringan gabungan (cabang dan loop).

- Alternatif 3 terpilih karena mempunyai nilai perkalian KPF dan KPA paling besar. Hal ini terjadi karena untuk alternatif 1 headloss-nya $>10 \mathrm{~m} / \mathrm{km}$, dan alternatif 2 kecepatan minimumnya $<0,3 \mathrm{~m} / \mathrm{dtk}$. 


\section{DAFTAR RUJUKAN}

Bappenas. (2003). Kebijakan Nasional Pembangunan Prasarana dan Sarana Air Minum dan Penyehatan Lingkungan Berbasis Lembaga. Bappenas-Departemen Permukiman dan Prasarana Wilayah-Departemen Kesehatan-Departemen Dalam Negeri.

Badan Perencanaan Pembangunan Nasional (Bappenas). (2014). Rencana Pembangunan Jangka Menengah Nasional (RPJMN) 2015-2019. Jakarta.

Badan Pusat Statistik, (2017). Kecamatan Bandung Kidul Dalam Angka. Bandung.

Badan Pusat Statistik, (2017). Kelurahan Batununggal Dalam Angka. Bandung.

Badan Pusat Statistik, (2017). Kelurahan Batununggal Dalam Angka. Bandung.

Khodijah, Siti. (2000). Analisis Sistem Pengelolaan Lingkungan. Jakarta-Indonesia.

PDAM Tirtawening Kota Bandung. (2017). Profil Perusahaan Daerah Air Minum Kota Bandung. PDAM Kota Bandung. Bandung.

Pemen PU No. 18 Tahun (2007). Tentang Penyelenggaraan Pengembangan Sistem Penyediaan Air Minum.

Permen PU No. 14 Tahun (2010). Tentang Standar Pelayanan Minimum Bidang Pekerjaan Umum dan Penataan Ruang.

Soleh, Ahmad Zanbar. (2006). Ilmu Statistika : Pendekatan Teoritis dan Aplikatif disertai Contoh Penggunaan SPSS. Bandung : Rekayasa Sains.

SNI 03-7065-(2005) Tentang Tata Cara Perencanaan Plumbing. 